\title{
Human mesenchymal stromal cells as cellular drug-delivery vectors for glioblastoma therapy: a good deal?
}

Anne Clavreul ${ }^{1,2^{*}}$, Milad Pourbaghi-Masouleh ${ }^{2,3}$, Emilie Roger ${ }^{4}$, Nolwenn Lautram ${ }^{4}$, Claudia N. Montero-Menei ${ }^{2}$ and Philippe Menei ${ }^{1,2}$

\begin{abstract}
Background: Glioblastoma (GB) is the most malignant brain tumor in adults. It is characterized by angiogenesis and a high proliferative and invasive capacity. Standard therapy (surgery, radiotherapy and chemotherapy with temozolomide) is of limited efficacy. Innovative anticancer drugs targeting both tumor cells and angiogenesis are urgently required, together with effective systems for their delivery to the brain. We assessed the ability of human mesenchymal stromal cells (MSCs) to uptake the multikinase inhibitor, sorafenib (SFN), and to carry this drug to a brain tumor following intranasal administration.
\end{abstract}

Method: MSCs were primed with SFN and drug content and release were quantified by analytical chemistry techniques. The ability of SFN-primed MSCs to inhibit the survival of the human U87MG GB cell line and endothelial cells was assessed in in vitro assays. These cells were then administered intranasally to nude mice bearing intracerebral U87MG xenografts. Their effect on tumor growth and angiogenesis was evaluated by magnetic resonance imaging and immunofluorescence analyses, and was compared with the intranasal administration of unprimed MSCs or SFN alone.

Results: MSCs took up about 9 pg SFN per cell, with no effect on viability, and were able to release $60 \%$ of the primed drug. The cytostatic activity of the released SFN was entirely conserved, resulting in a significant inhibition of U87MG and endothelial cell survival in vitro. Two intranasal administrations of SFN-primed MSCs in U87MG-bearing mice resulted in lower levels of tumor angiogenesis than the injection of unprimed MSCS or SFN alone, but had no effect on tumor volume. We also observed an increase in the proportion of small intratumoral vessels in animals treated with unprimed MSCs; this effect being abolished if the MSCs were primed with SFN.

Conclusion: We show the potential of MSCs to carry SFN to brain tumors following an intranasal administration. However, the therapeutic effect is modest probably due to the pro-tumorigenic properties of MSCs, which may limit the action of the released SFN. This calls into question the suitability of MSCs for use in GB therapy and renders it necessary to find methods guaranteeing the safety of this cellular vector after drug delivery.

Keywords: Drug delivery, Glioblastoma, Mesenchymal stromal cells, Targeting, Sorafenib

\footnotetext{
* Correspondence: anne.clavreul@univ-angers.fr

${ }^{1}$ Département de Neurochirurgie, CHU, Angers, France

${ }^{2}$ CRCINA, INSERM, Université de Nantes, Université d'Angers, Angers, France

Full list of author information is available at the end of the article
} 


\section{Background}

Glioblastoma (GB) is the most common, invasive and aggressive primary brain tumor in humans. Over the last 12 years or so, most patients with GB have been treated with the Stupp protocol [1], consisting of surgical resection followed by radiotherapy with concomitant and adjuvant temozolomide (TMZ) chemotherapy. The efficacy of this treatment is limited, with median overall survival of no more than 15 months [2]. GB treatment is complicated by the high resistance of these tumors to standard chemotherapy agents, the critical role of angiogenesis in their growth and spread and the blood-brain barrier (BBB), which serves as a physiological obstacle to the delivery of drugs to the central nervous system. The development of innovative anticancer drugs targeting both tumor cells and blood vessels is therefore urgently required, together with effective systems for delivering these drugs to the brain.

In recent years, targeted molecular therapies based on the use of inhibitors of several pathways involved in the oncogenic process in GB have emerged [3-5]. Sorafenib (SFN) (Nexavar) is one such inhibitor. It is an oral multikinase inhibitor that targets both cell surface kinase receptors (VEGFR and PDGFR) and downstream intracellular serine/ threonine kinases [6] resulting in diverse cellular effects, such as induction of tumor cell apoptosis and autophagy, and reduction of angiogenesis [7-9]. SFN showed efficacy against different solid tumors and is already approved for the treatment of advanced hepatocellular carcinoma, renal cell carcinoma, and thyroid cancer [6]. In clinical studies in patients with progressive or recurrent GB, oral administration of SFN has been shown to be of very limited efficacy as a monotherapy or in combination with TMZ or other targeted drugs, such as erlotinib [10-16]. This lack of efficacy is not restricted to SFN; other drugs fell short of expectations because they penetrated the brain only inefficiently via the $\mathrm{BBB}$ or were unable to target tumor cells. Various approaches have been developed to overcome these limitations, including the use of mesenchymal stromal cells (MSCs), which can cross the BBB and display brain tumor tropism after systemic and local administration [17-21]. This property has generated considerable interest in the use of MSCs as treatment vectors for GB [22-25].

MSCs have been genetically modified to overexpress several antitumor factors, such as interleukins, interferons, pro-drugs, oncolytic viruses, anti-angiogenic agents, proapoptotic proteins, and growth factor antagonists [26, 27]. Despite promising results in animal models, the genetic manipulation of MSCs for clinical application is not riskfree [28]. We and others have shown that MSCs can deliver chemotherapy drugs to brain tumors without genetic modification [29-33]. For example, we have shown that MSCs can deliver lipid nanocapsules containing an organometallic complex (ferrociphenol) in the heterotopic and orthotopic U87MG GB models [29, 31]. MSCs were also able to take up and release paclitaxel and to induce cytotoxic damage in GB xenografts $[32,34]$. A major concern to use these therapeutic cells is the delivery method. The surgical injection of MSCs directly into the brain is the most frequently used method of delivery. However, this method is invasive making a repeated treatment option difficult. In a clinical context, systemic administration of this therapeutic tool would be simpler, less costly and would allow for a chronic treatment. Intravascular applications of MSCs could be an option but major obstacles are the entrapment and elimination of cells in peripheral organs and the risk of vascular and pulmonary embolization [35, 36]. Intranasal administration of MSCs appears to be a promising noninvasive and safe alternative delivery method to surgical injection or to intravascular administration [37]. Intranasally administered MSCs were able to enter the brain in experimental glioma models [19] as well as in mouse models of Alzheimer's and Parkinson's disease [38] and neonate ischemic brain damage models [39].

In this study, we evaluated the ability of MSCs to take up SFN and target it to the tumor in the orthotopic U87MG GB model, following intranasal administration. We paid particular interest to the effects of SFN-primed MSCs on tumor growth and angiogenesis, through comparisons with the intranasal administration of unprimed MSCs or SFN alone.

\section{Methods}

\section{Cell culture and reagents}

MSCs were obtained from iliac crest aspirates from a human male post-mortem organ donor (protocol agreed by the French Agency of Biomedicine), and were isolated as previously described $[17,40]$. This cell population was expanded by culture in StemMACS ${ }^{\mathrm{sm}}$ MSC Expansion Media Kit XF (Miltenyi Biotec, Paris, France) in a humidified incubator at $37{ }^{\circ} \mathrm{C}$, under an atmosphere containing $5 \% \mathrm{CO}_{2}$, until $70 \%$ confluence. All experiments were performed with cells between passages 4 and 5 .

The human U87MG GB cell line was obtained from the ATCC (LGC Promochem, Molsheim, France). Cells were maintained in Dulbecco's modified eagle medium-high glucose medium (DMEM-HG, Lonza, Verviers, Belgium) containing 10\% fetal bovine serum (FBS) (Fisher Scientific, Illkirch, France) and 1\% antibiotics (Sigma-Aldrich, St. Quentin Fallavier, France), under an atmosphere containing $5 \% \mathrm{CO}_{2}\left(37{ }^{\circ} \mathrm{C}\right)$, in a humidified incubator, until they reached $80 \%$ confluence.

Human umbilical vein endothelial cells (HUVECs) were purchased from Lonza. Cells were cultured according to the supplier's instructions, in endothelial cell growth medium-2 (EGM-2) in a humidified chamber at $37{ }^{\circ} \mathrm{C}$, under an atmosphere containing $5 \% \mathrm{CO}_{2}$. 
SFN was purchased from LC Laboratories (Woburn, USA). The stock solution was prepared in DMSO (SigmaAldrich), at a concentration of $100 \mathrm{mM}$. Aliquots were stored at $-20{ }^{\circ} \mathrm{C}$.

\section{Sensitivity of HUVECs, U87MG and MSCs to SFN}

HUVECs and U87MG cells were plated in 96-well plates at densities of $5 \times 10^{3}$ cells $/ \mathrm{cm}^{2}$ and MSCs were plated at a density of $1 \times 10^{4}$ cells $/ \mathrm{cm}^{2}$. After $48 \mathrm{~h}$, the culture medium was removed and cells were treated with SFN at concentrations of 0.001 to $100 \mu \mathrm{M}$. Four days later, the medium was removed from the wells and the plates were stored at $-80{ }^{\circ} \mathrm{C}$ until their use for assays. Cell survival was estimated with the CyQUANT ${ }^{\circ}$ cell proliferation assay kit, according to the manufacturer's instructions (Fisher Scientific).

\section{Priming of MSCs with SFN}

MSCs $\left(4 \times 10^{5}\right.$ cells $)$ were incubated for $1 \mathrm{~h}$ at $37^{\circ} \mathrm{C}$ with $1 \mathrm{~mL}$ SFN (20 or $100 \mu \mathrm{M})$ in Hank's balanced salt solution (HBSS), with $\mathrm{Ca}^{2+}$ and $\mathrm{Mg}^{2+}$ (Lonza). At the end of the incubation period, cells were washed twice with HBSS, counted, and used for in vitro and in vivo experiments, as described below.

\section{In vitro characterization of SFN-primed MSCs SFN content of SFN-primed MSCS}

The SFN content of MSCs was measured by high performance liquid chromatography (HPLC) method. SFNprimed MSCs $\left(4 \times 10^{5}\right.$ cells $)$ were suspended in $50 \mu \mathrm{L}$ $\mathrm{H}_{2} \mathrm{O}$. We then successively added $50 \mu \mathrm{L}$ tetrahydrofuran and $200 \mu \mathrm{L}$ methanol. A filtration was performed using a Millex-LG $0.2 \mu \mathrm{m}$ filter (Millipore, Guyancourt, France) and $10 \mu \mathrm{L}$ was injected onto the HPLC system. Chromatography was performed with the Waters modular system (600/717/996/2414) (Waters, Saint-Quentin-en-Yvelynes, France) on a SunFire $\mathrm{C} 18$ column $(150 \times 4.6 \mathrm{~mm} ; 5 \mu \mathrm{m})$ at $37{ }^{\circ} \mathrm{C}$. SFN was eluted with an isocratic mobile phase (acetonitrile/methanol/1\% acetic acid, at a ratio of 35:38:27) at a flow rate of $1 \mathrm{~mL} / \mathrm{min}$, with monitoring at $266 \mathrm{~nm}$. The chromatograms were recorded and integrated with Empower 3 software (Waters). The range of linear response was $0.5-32 \mu \mathrm{g} / \mathrm{mL}$.

\section{Viability of SFN-primed MSCS}

SFN-primed MSCs were used to seed 96-well plates, and cell survival was estimated one and seven days later, with the CyQUANT $^{\circ}$ cell proliferation assay kit, as described above.

\section{Release of SFN from SFN-primed MSCS}

SFN-primed MSCs $\left(3 \times 10^{5}\right)$ were used to seed Transwell inserts with a pore size of $0.4 \mu \mathrm{m}$ (Millipore) in DMEM-HG supplemented with $10 \% \mathrm{FBS}$ and $1 \%$ antibiotics. We monitored SFN release at different time points, by collecting the cell-conditioned medium (CM) from the lower compartment at 4, 24, 48, 72 and $96 \mathrm{~h}$. Quantification of SFN in the $\mathrm{CM}$ was determined by liquid chromatography tandemmass spectrometry (LC-MS/MS).

Chromatography was performed with the Waters Alliance 2695 system, with an Uptisphere 5 ODB C18 column $(150 \times 2.0 \mathrm{~mm})$ (Interchim, Montluçon, France). The mobile phase consisted of an isocratic mixture of $0.1 \%$ formic acid in water $/ 0.1 \%$ formic acid in acetonitrile: $20 / 80$ $(v / \mathrm{v})$. The column temperature was set at $25{ }^{\circ} \mathrm{C}$ and the flow rate was $0.3 \mathrm{~mL} / \mathrm{min}$, with a total run time of $10 \mathrm{~min}$. The total HPLC effluent was analyzed in a Quattro $^{\circ}$ Micro triple quadrupole mass spectrometer (Waters). Ionization was achieved by the electrospray method, in positive-ion mode. The mass spectrometer was operated in multiple reaction monitoring (MRM) mode. The $(\mathrm{M}-\mathrm{H})+\mathrm{m} / \mathrm{z}$ transition for SFN was $465 \rightarrow 270$. A typical retention time for SFN was $2.3 \mathrm{~min}$. Quantification was achieved with QuantLynx ${ }^{\circ}$ (Waters), by comparing the observed peak area ratios of SFN samples with a calibration curve obtained under the same experimental conditions. The range of the linear response was large, extending from 50 to $1000 \mathrm{ng} / \mathrm{mL}$.

\section{Toxicity of SFN-primed MSCs to U87MG cells and HUVECS}

We assessed the in vitro toxicity of SFN-primed MSCs to U87MG cells and HUVECs, by performing coculture experiments in Transwell $^{\bullet}$ plates, with inserts with a pore size of $0.4 \mu \mathrm{m}$ (Millipore). HUVECs and U87MG cells $\left(6 \times 10^{3}\right.$ cells/well $)$ were placed in the lower compartment. After $48 \mathrm{~h}$, we added SFN, or unprimed or SFN-primed MSCs to the upper compartment. Three days later, the inserts were removed and a CyQUANT ${ }^{\circ}$ cell proliferation assay was performed.

\section{In vivo effect of SFN-primed MSCs U87MG GB model}

Female Swiss nude mice (8-10 weeks old) were obtained from Charles River Laboratories (L'Arbresle, France). The protocol was approved by the Committee on the Ethics of Animal Experiments of the "Pays de la Loire" (Permit no. 01785.01). Animals were anesthetized by an intraperitoneal injection of xylazine $(13 \mathrm{mg} / \mathrm{kg}$ body weight) and ketamine (100 mg/kg body weight) and were positioned in a Kopf stereotaxic instrument. On day 0 (D0), U87MG cells $\left(3 \times 10^{4}\right)$ in $5 \mu \mathrm{L}$ HBSS with $\mathrm{Ca}^{2+}$ and $\mathrm{Mg}^{2+}$ were injected into the striatum of mice [coordinates: $2.1 \mathrm{~mm}$ lateral to the bregma, $0.5 \mathrm{~mm}$ anterior and $3 \mathrm{~mm}$ interior to the outer border of the cranium].

\section{Analysis of the distribution of MSCs in the U87MG tumor after their intranasal administration}

Intranasal delivery was performed as previously described [19], but with minor modifications. Thirty minutes before 
cell administration, anesthetized U87MG tumor-bearing mice (D12) were placed in a supine position and the nasal cavity of each animal was treated with total of $100 \mathrm{U}$ hyaluronidase (Sigma-Aldrich) in the form of four repeated inoculations at two-minute intervals (3 $\mu \mathrm{L}$ per nostril). We then applied either HBSS with $\mathrm{Ca}^{2+}$ and $\mathrm{Mg}^{2+}$, or $6 \times 10^{5} \mathrm{MSCs}$ in the same conditions. For analysis of the distribution of MSCs in the U87MG tumor, the animals were killed three or seven days later (D15 and D19, respectively). Brains were snap-frozen in isopentane cooled with liquid nitrogen and stored at $-80{ }^{\circ} \mathrm{C}$. Coronal sections of the brain were cut at $10 \mu \mathrm{m}$ intervals and collected on silane-treated slides. MSCs in tumor cryosections were detected by fluorescence in situ hybridization (FISH), with a human Y-chromosome probe, as previously described [34]. The DNA probe was complementary to the highly repetitive human satellite III sequences located close to the centromeric region of the human Y-chromosome DYZ1 locus (CEPY) and was labeled with the SpectrumOrange fluorochrome (Vysis, Abbott Molecular, Rungis, France).

Cryosections of four mice killed at day 15 or day 19 were analyzed under a fluorescence microscope (Axioscope 2 light microscope, Zeiss, Le Pecq, Germany). $\mathrm{Y}^{+}$MSCs were counted on nine cryosections per mouse corresponding to the central and peripheral portions of the tumor, with the MetaView computerized image-analysis system (Roper Scientific, Evry, France). About five fields per cryosection, at a magnification of $\times 200$, were randomly selected for each tumor.

\section{Analysis of the effect of SFN-primed MSCs in the orthotopic U87MG GB model}

U87MG tumor-bearing mice (D6) were assigned to four groups receiving intranasal injections according to the protocol described above: (a) HBSS with $\mathrm{Ca}^{2+}$ and $\mathrm{Mg}^{2+}$; (b) SFN; (c) unprimed MSCs; (d) SFN-primed MSCs. These injections were repeated on day 10. Seven days later, we measured tumor volume by magnetic resonance imaging (MRI), as previously described [31], and the mice were killed for the analysis of $\mathrm{Ki}^{+} 7^{+}$cells or $\mathrm{CD} 31^{+}$vessels in the U87MG tumor. The presence of intratumoral $\mathrm{Y}^{+}$ MSCs in all U87MG tumor-bearing mice treated with unprimed or SFN-primed MSCs was checked by FISH. For CD31 and Ki67 expression analysis, brain cryosections were allowed to dry in air, rehydrated in PBS and fixed by incubation for $10 \mathrm{~min}$ in $4 \%$ PFA pH 7.4 at $4{ }^{\circ} \mathrm{C}$. Nonspecific binding was blocked by incubating the sections in $4 \%$ BSA and $10 \%$ normal goat serum in PBS. The sections were incubated overnight, at $4{ }^{\circ} \mathrm{C}$, with isotype controls and primary antibodies against endothelial cells (mouse CD31, BD Biosciences, Le Pont de Claix, France ) and proliferative cells (Ki67, Agilent Technologies, Les Ulis, France). The primary antibodies were detected with biotinylated secondary antibodies and the signal was amplified with streptavidin-FITC (Interchim). Nuclei were counterstained with DAPI (Sigma). Cryosections of four mice from each of the groups described above ( $a, b, c$ and d) were analyzed under an Axioscope 2 fluorescence microscope. $\mathrm{CD} 1^{+}$and $\mathrm{Ki}^{+} 7^{+}$cells were counted with the MetaView computerized image-analysis system in six brain cryosections per mouse corresponding to the central and peripheral portions of the tumor. Five fields per cryosection, at $\times 200$ magnification, were randomly selected for each tumor.

\section{Statistical analysis}

Results are expressed as means \pm SEM. The KruskalWallis test was used for statistical analyses. Differences were considered significant if the $p$-value was $<0.05$.

\section{Results}

Effect of SFN on the survival of U87MG cells, HUVECs and MSCs

Both U87MG cells and HUVECs displayed dose-dependent survival inhibition when treated for 4 days with SFN (Fig. 1). SFN decreased cell viability with an $\mathrm{IC}_{50}$ of $7.39 \pm 0.16 \mu \mathrm{M}$ for U87MG cells and $1.91 \pm 0.19 \mu \mathrm{M}$ for HUVECs. MSCs displayed relative resistance to SFN treatment (about $40 \%$ cell death at $100 \mu \mathrm{M})$.

\section{SFN content of SFN-primed MSCs and control of their viability}

We defined the dose of SFN that MSCs could carry without deleterious effects on their viability. For this purpose, MSCs $\left(4 \times 10^{5}\right)$ were incubated for $1 \mathrm{~h}$ at $37^{\circ} \mathrm{C}$ with $20 \mu \mathrm{M}(9.2 \mu \mathrm{g} / \mathrm{mL})$ or $100 \mu \mathrm{M}(46 \mu \mathrm{g} / \mathrm{mL})$. MSCs primed with $20 \mu \mathrm{M}$ and $100 \mu \mathrm{M}$ were carrying $8.8 \pm 0.5$ and $52.7 \pm 5.0 \mathrm{pg}$ SFN per cell, respectively (Fig. 2a). The incubation of MSCs with $100 \mu \mathrm{M}$ SFN resulted in a $40 \%$ loss of cell viability 1 day after uptake, whereas $80 \%$ of MSCs remained viable when incubated with $20 \mu \mathrm{M}$ SFN (Fig. 2b). Seven days after priming, no additional loss of viability was observed in either set of conditions and SFN-primed MSCs retained their capacity to proliferate (data not shown). Given the lower cell viability observed following the incubation of MSCs with $100 \mu \mathrm{M}$ SFN, we decided to prime MSCs with $20 \mu \mathrm{M}$ SFN.

\section{Quantification and toxicity of the SFN released by SFN- primed MSCs}

We evaluated the release of SFN over time, by collecting the CM from SFN-primed MSCs 4, 24, 48, 72 and $96 \mathrm{~h}$ after priming with SFN $(20 \mu \mathrm{M})$ and analyzing it by LC-MS/MS. We found that about $20 \%$ of the SFN was released from SFN-primed MSCs in $4 \mathrm{~h}$, and that $60 \%$ of the drug was released in $48 \mathrm{~h}$ (Fig. 3a). No further increase was observed for longer incubation 


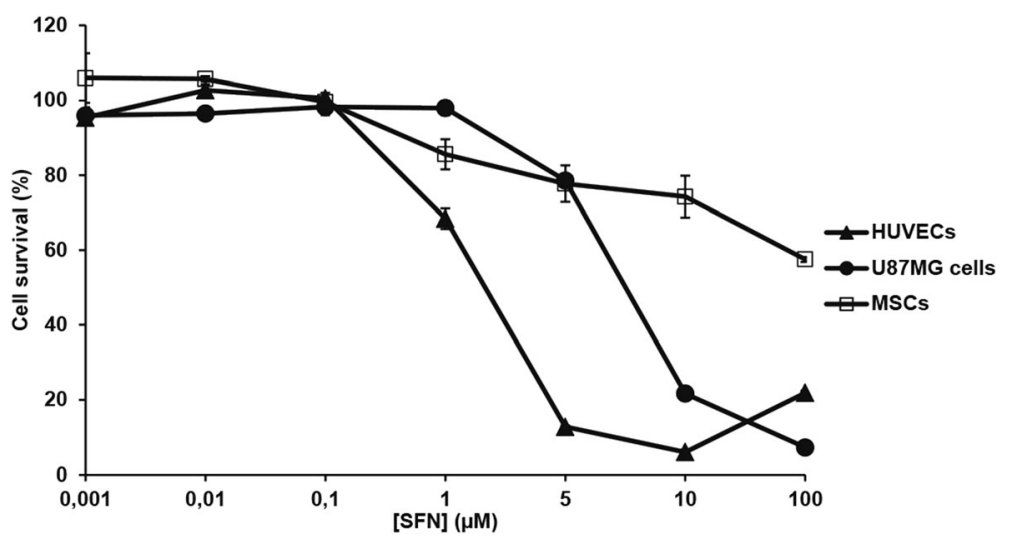

Fig. 1 Effect of SFN on cell survival. U87MG cells, HUVECS and MSCs were seeded in their standard growth media and were treated with various concentrations of SFN. Cell survival was estimated with the CyQUANT ${ }^{\oplus}$ cell proliferation assay kit. The results obtained for U87MG cells, HUVECs or MSCs cultured with culture medium alone were considered to correspond to 100\% survival. Data are expressed as the mean of four wells \pm $\operatorname{SEM}(n=3)$

periods. We therefore estimated that about $40 \%$ of the SFN was retained by the cells. This result was confirmed in a cytotoxicity assay on U87MG cells and HUVECs (Fig. $3 \mathrm{~b}, \mathrm{c})$. We found that, after 3 days, $6 \times 10^{5}$ SFN-primed MSCs, corresponding to the release of approximately $3.2 \mu \mathrm{g}$ SFN, decreased U87MG cell survival by $23 \%$, whereas $6 \times 10^{5}$ unprimed MSCs had no effect on U87MG cell viability (Fig. 3b). This decrease in survival is intermediate between those induced by $2 \mu \mathrm{g}$ and $6 \mu \mathrm{g}$ of SFN (Fig. 3b). A similar result was obtained with HUVECs, in which $2 \times 10^{5}$ SFN-primed MSCs, corresponding to the release of approximately $1.1 \mu \mathrm{g}$ SFN, decreased cell survival by $37 \%$, a value close to that induced by $1.5 \mu \mathrm{g}$ SFN (35\%) (Fig. 3c).

\section{Analysis of the effects of the intranasal administration of SFN-primed MSCs on U87MG growth and angiogenesis} We first controlled by FISH, the intratumoral distribution of MSCs following intranasal administration in U87MG tumor-bearing mice (D12, tumor volume: $2.9 \pm 0.2 \mathrm{~mm}^{3}$ estimated by MRI) $(n=8)$ (Fig. 4a). Three days after intranasal administration of MSCs, we observed MSCs in the

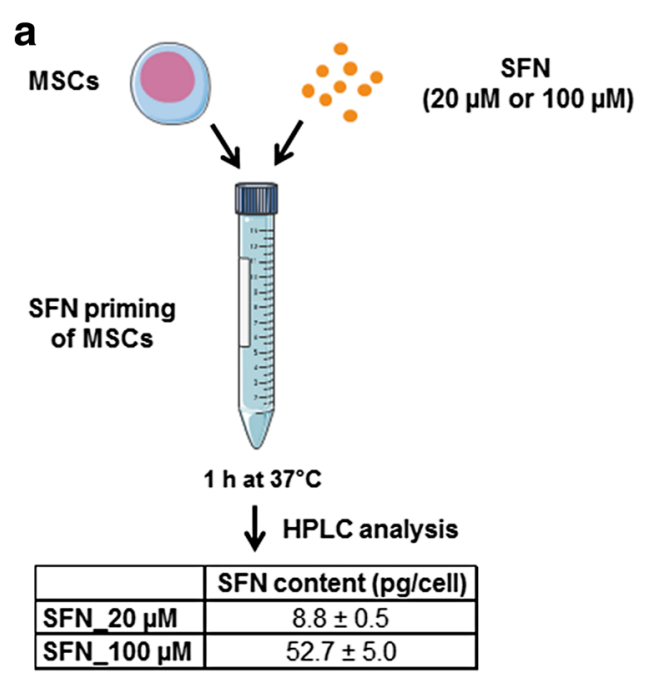

b

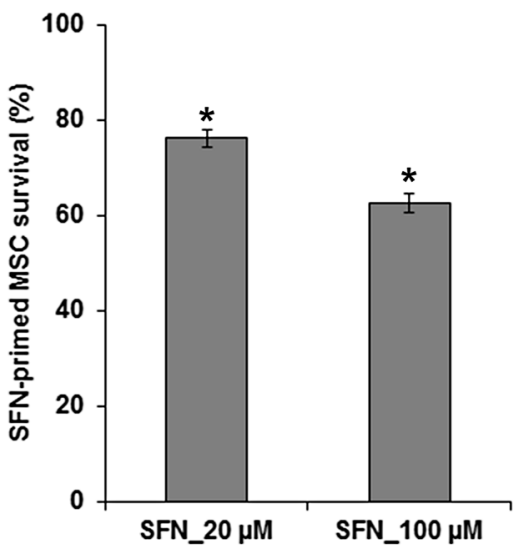

Fig. 2 SFN content in primed MSCS and control of their viability. a Determination of the SFN content of primed MSCs. MSCS were incubated for $1 \mathrm{~h}$ at $37^{\circ} \mathrm{C}$ with SFN $(20 \mu \mathrm{M}$ or $100 \mu \mathrm{M})$. After washing with HBSS, the SFN content of the cell pellet was determined by HPLC. $\mathbf{b}$ Determination of the viability of SFN-primed MSCs. MSCs were incubated for $1 \mathrm{~h}$ at $37^{\circ} \mathrm{C}$ with or without SFN (20 $\mu \mathrm{M}$ or $\left.100 \mu \mathrm{M}\right)$. After washing with HBSS, cells were seeded in a 96-well plate. Cell survival was estimated after $24 \mathrm{~h}$, with the CyQUANT ${ }^{\circledR}$ cell proliferation assay kit. The results obtained for unprimed MSCs were considered to correspond to $100 \%$ survival. Data are expressed as the mean of three independent experiments \pm SEM. Asterisks $\left(^{*}\right)$ indicate significant differences from unprimed MSCs $(p<0.05)$ 


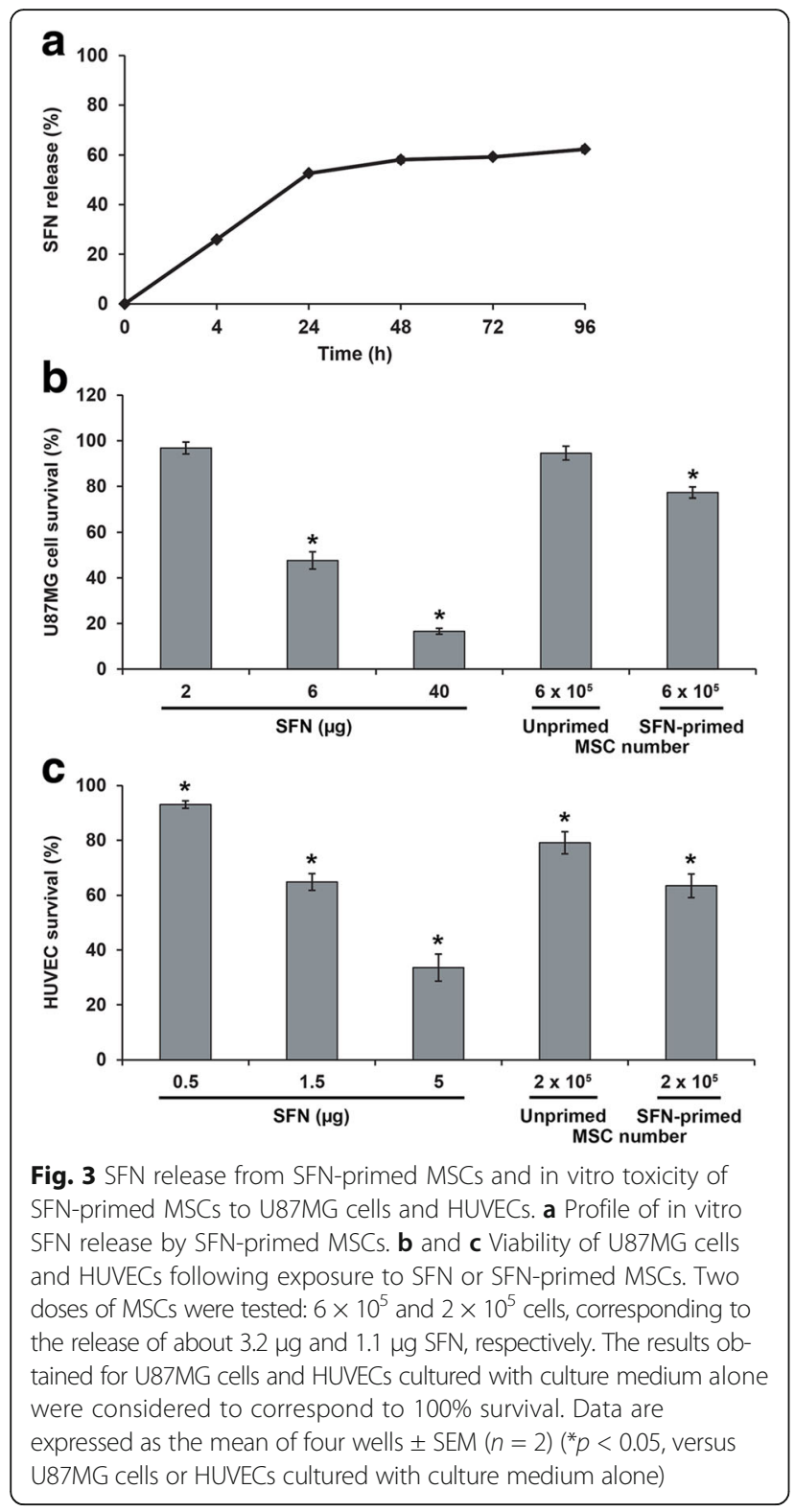

tumor mass and at the border zone between the tumor and the normal parenchyma, consistent with tumordirected tropism (Fig. 4b). The tumor contained a mean of $157 \pm 27$ cells $/ \mathrm{mm}^{2}$ (Fig. 4c). Seven days after intranasal administration, the number of MSCs in the tumor increased to a mean of $403 \pm 82$ cells $/ \mathrm{mm}^{2}$ (Fig. 4c). The MSCs were evenly distributed throughout the whole tumor (data not shown). Intranasally administered MSCs were also able to migrate towards smaller U87MG tumors (D6, tumor volume: $1.2 \pm 0.1 \mathrm{~mm}^{3}$ estimated by MRI) and this migration was unaffected by priming with SFN (data not shown).

The effect of two intranasal administrations of SFNprimed MSCs was then assessed on U87MG growth and angiogenesis (Fig. 5a). For this purpose, U87MG tumor- bearing mice were treated on day 6 with SFN, or with unprimed or SFN-primed MSCs, in amounts corresponding to an SFN dose of about $5.3 \mu \mathrm{g} /$ mouse. This dose caused in vitro U87MG cell and HUVEC mortality rates of close to $40 \%$ and $70 \%$, respectively. A control group receiving intranasal administrations of HBSS rather than treatment was also established. This injection protocol was repeated on day 10. Seven days later, we assessed tumor volume, and the numbers of intratumoral $\mathrm{Ki} 67^{+}$proliferative cells and $\mathrm{CD}_{3} 1^{+}$vessels. Intranasal administrations of SFN, or of unprimed or SFN-primed MSCs had no effect on tumor volume (Fig. 5b). There was no significant difference in the number of intratumoral $\mathrm{Ki} 67^{+}$cells between control and treated mice (Fig. 5c, d). Nevertheless, mice receiving intranasal administrations of unprimed MSCs had slightly higher levels of angiogenesis: they had significantly more small vessels $\left(<100 \mu \mathrm{m}^{2}\right)$ than mice receiving intranasal administrations of HBSS, SFN or SFN-primed MSCs (Fig. 5c, e). This effect was attenuated by the priming of MSCs with SFN. Furthermore, SFN-primed MSCs induced a significant decrease in the number of large vessels (> $100 \mu^{2}$ ) relative to HBSS, SFN and unprimed MSCs (Fig. 5c, e).

\section{Discussion}

The best approach to chemotherapy for cancer is to deliver the drug to the tumor microenvironment, to kill tumor cells whilst maintaining the lowest possible level of lethal damage to healthy cells, so as to limit deterioration of the patient's quality of life. Many approaches to achieving this objective have been proposed, including the use of MSCs, which can take up drugs and home to tumors when administered systemically in vivo [41].

We show here that MSCs can be primed in vitro with SFN, a targeted chemotherapy drug. We showed that a priming concentration of $100 \mu \mathrm{M}$ SFN caused $40 \%$ toxicity in MSCs, whereas a priming concentration of $20 \mu \mathrm{M}$ was only moderately cytotoxic (about 20\%). This concentration was selected to ensure that a sufficient number of MSCs reached the brain tumor after an intranasal delivery. HPLC analysis showed that MSCs primed with $20 \mu \mathrm{M}$ SFN contained a dose of about 9 pg SFN per cell and were able to release $60 \%$ of the drug into the culture medium, in a time-dependent manner. This result is consistent with the findings of Pessina et al. (2011) [34] who estimated that about $25-30 \%$ of PTX was retained by PTX-primed MSCs and never released. The cytostatic activity of the released SFN was entirely conserved, resulting in the significant inhibition of U87MG cell and HUVEC proliferation in vitro. The mechanisms by which MSCs excreted SFN did not seem to involve MSC death since $80 \%$ of MSCs remained viable seven days after priming with SFN. Further work is required to determine the route by which SFN leaves MSCs, but recent studies have 


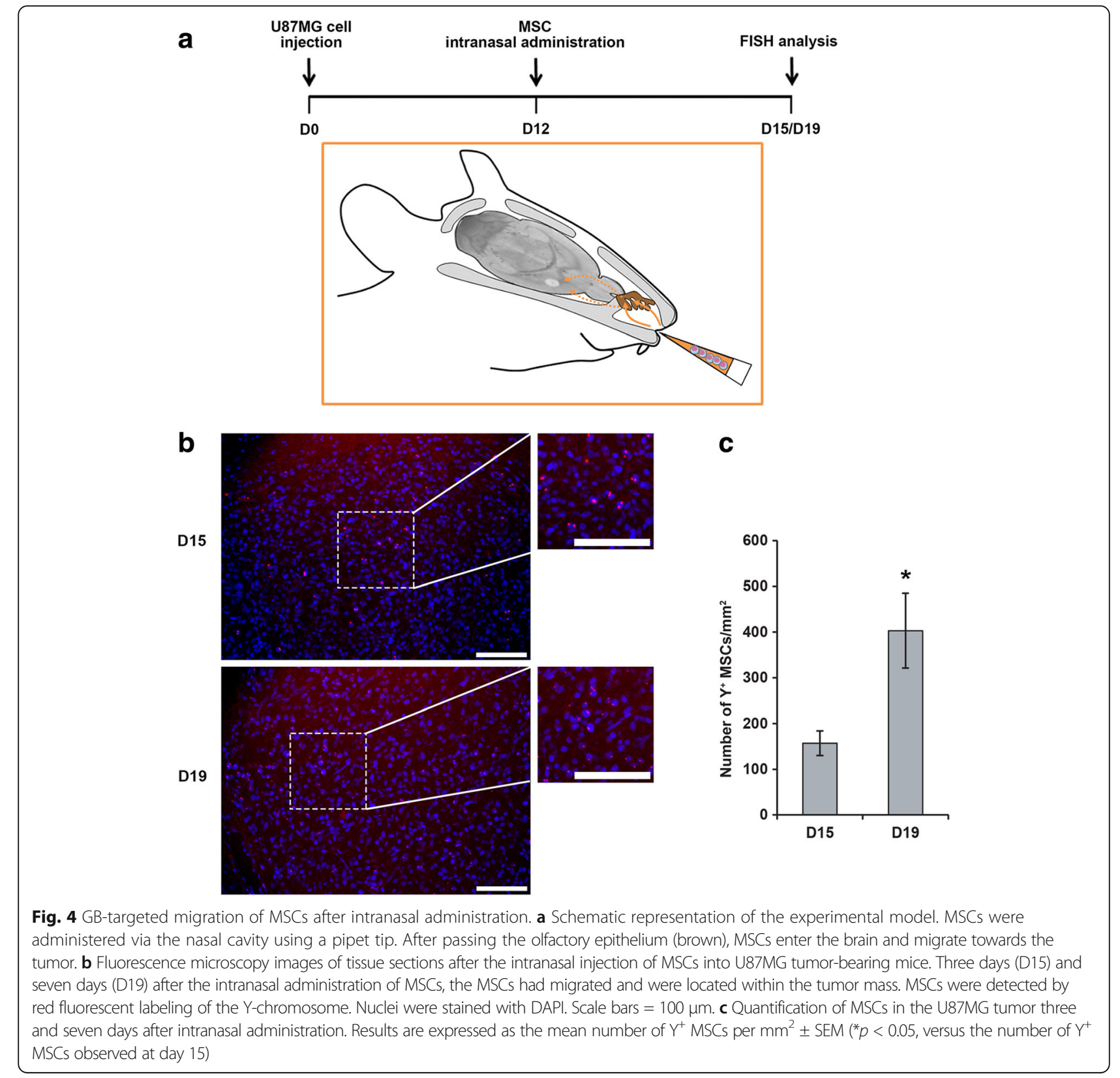

suggested that MSCs deliver drugs by secreting membrane microvesicles [42, 43].

We investigated the in vivo effect of SFN-primed MSCs on the orthotopic U87MG GB model, following their intranasal administration. Intranasal delivery has the advantage over direct intracranial deliver of being noninvasive, making repeated treatment regimens possible. Balyasnikova et al. (2014) [19] showed, with various technical approaches ( ${ }^{111}$ In-oxine, MRI and bioluminescence imaging), that MSCs could penetrate the brain from the nasal cavity and infiltrate intracranial glioma xenografts in a mouse model. We validated their results with another approach, FISH technique, which can be used for the specific tracking of male-derived MSCs in female nude mice bearing U87MG tumors, through detection of the Ychromosome. Three days after the intranasal administration of $6 \times 10^{5}$ MSCs, these cells had accumulated in the U87MG tumor, with a mean of $157 \pm 27$ cells $/ \mathrm{mm}^{2}$, and even greater accumulation was observed after seven days. These findings are similar to those of Reitz et al., (2012) [44], who reported a mean accumulation of $54 \pm 13$ cells/ $\mathrm{mm}^{2}$ in U87MG tumors five days after the intranasal administration of $3 \times 10^{5}$ neural stem/progenitor cells. The accumulation of MSCs in U87MG was analyzed three days post-MSC administration to be sure that a sufficient number of cells could be detected by FISH but part of 


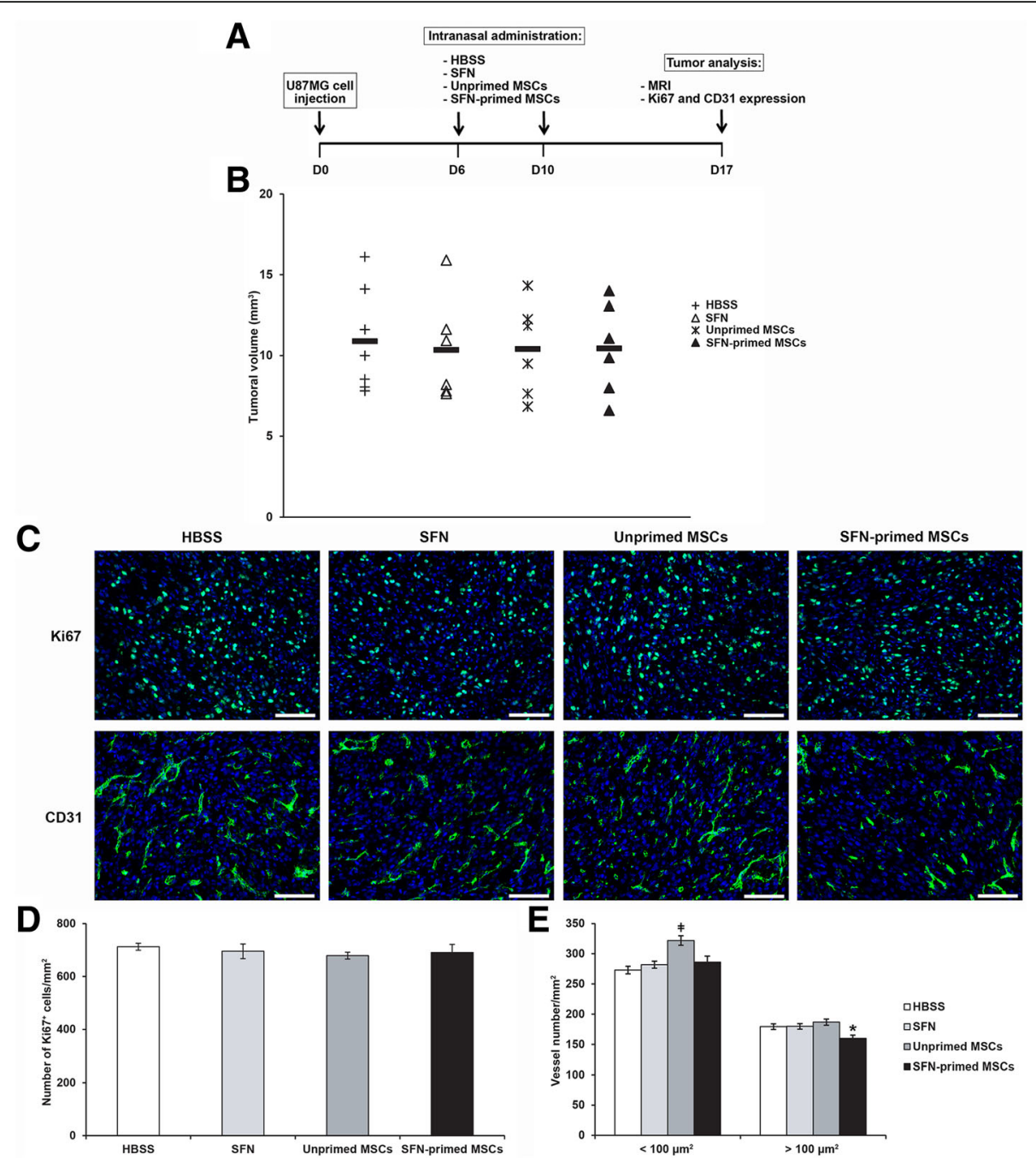

Fig. 5 Effect of intranasal administrations of SFN, or of unprimed or SFN-primed MSCS on U87MG growth and angiogenesis. a Representation of the treatment protocol applied to U87MG-bearing mice. b Tumor volume distribution in each group, calculated by MRI on day 17. c Immunofluorescence staining for Ki67 and CD31 in the tumor on day 17 (scale bar = $100 \mu \mathrm{m}$ ). $\mathbf{d}$ and e Quantitative results for Ki67 and CD31 immunofluorescence. Results are expressed as the mean number of Ki67 $7^{+}$cells (d) or CD31 $1^{+}$vessels (e) per $\mathrm{mm}^{2} \pm$ SEM. $(\neq p<0.05$, versus HBSS, SFN and SFNprimed MSCs; ${ }^{*} p<0.05$, versus HBSS, SFN and unprimed MSCs)

MSCs might have reached the tumor as early as $24 \mathrm{~h}$ as observed by Balyasnikova et al. (2014) [19]. These same authors analyzed the distribution of MSCs using ${ }^{111}$ Inoxine-labeled MSCs and demonstrated the presence of MSCs in the lung and stomach after intranasal delivery. It is difficult to specify if MSCs accumulate in the brain long-term or if they are cleared out from the brain because the survival time of tumor-bearing animals is short. In our previous study [17], we assessed the fate of MSCs seven days after being injected into intracranial U87MG tumors and compared it to the fate of MSCs injected into the striatum of healthy mice. MSCs did not seem to clear out from the brain. We observed that 20\% of MSCs expressed Ki67 proliferation marker in the U87MG environment. In the healthy environment, we found no MSCs in a proliferative state suggesting that factors produced by the U87MG cells induced MSC proliferation. We observed that MSCs can migrate towards large or small U87MG tumors. This is important in a clinical context because GB is highly invasive with an infiltration that can extend several centimeters deep beyond the radiological limits of the tumor [45]. Furthermore, as previously described for other modified MSCs, the priming of MSCs with SFN did not prevent their migration after intranasal administration $[18,19]$.

The treatment of U87MG tumor-bearing mice with two intranasal administrations of $6 \times 10^{5}$ SFN-primed MSCs four days apart reduced tumor angiogenesis, resulting in a significant decrease of the number of large vessels. No decrease in angiogenesis was observed 
following the intranasal administration of SFN alone, highlighting the potential value of MSCs as a vector for transporting SFN to the intracerebral tumor following administration via this route. We did not observe an effect of SFN-primed MSCs on tumor volume or the proportion of $\mathrm{Ki} 67^{+}$cells in the tumor. The absence of this effect is probably due to an insufficient dose of SFNprimed MSCs. Siegelin et al. (2010) [8] observed that a daily treatment of U87MG-bearing mice with SFN $(100 \mathrm{mg} / \mathrm{kg})$ by intraperitoneal injections resulted in an inhibition of tumor cell proliferation and reduction of angiogenesis with a prolonged survival of mice. We injected only two doses of SFN-primed MSCs (about $5.3 \mu \mathrm{g} /$ mouse), a lower dose than was used in the study of Siegelin et al. corresponding to about $2 \mathrm{mg} / \mathrm{mouse} /$ day. The dose of SFN carried by MSCs in our study corresponded to an effective dose reducing U87MG cell survival in vitro, but was ineffective against U87MG cells in vivo. However, it may be sufficient to have affected endothelial cells, which are four times more sensitive to SFN than U87MG cells. The intranasal administration of larger numbers of SFN-primed MSCs may be required for an effect on U87MG growth. However, if we look at global literature data on the use of modified MSCs to treat GB, we notice that the effect of these cells on animal survival is relatively modest, whatever the route of administration and the number of administrations. For example, regarding the intranasal route, Balyanikova et al. (2014) [19] showed that the treatment of irradiated mice bearing intracranial U87EGFRvIII GB xenografts by four intranasal administrations of $5 \times 10^{5}$ MSCs expressing TNF-related apoptosis inducing ligand at one-week intervals prolonged survival of mice of about ten days compared with irradiated mice treated with control MSCs. Similarly, Mangraviti et al. (2016) [18] observed that the treatment of athymic rats bearing human brain tumor-initiating cells by two intranasal inoculations of $2 \times 10^{6}$ human adipose-derived MSCs (hAMSCs) producing bone morphogenetic protein 4 one week apart induced a $21.4 \%$ increase in median survival over that in rats treated with control hAMSCs.

The modest effect of therapeutic MSCs on GB growth inhibition may be due to the pro-tumorigenic and proangiogenic properties of these cells. Even if the role of MSCs in cancer progression remains a matter of heated debate, increasing numbers of studies are highlighting these properties [41, 46-48]. In line with these studies, we found that the intranasal administration of unprimed MSCs induced a significant increase of the number of small vessels in the U87MG tumor, which was abolished when MSCs were primed with SFN. Different studies indicate that MSCs promote angiogenesis by secreting angiogenic factors, such as VEGF, releasing exosomes, recruiting endothelial progenitors, and/or transdifferentiating into endothelial cells $[49,50]$. The mechanisms by which SFN inhibited the angiogenic properties of MSCs need to be elucidated. Even though we did not observe an effect of unprimed MSCs on tumor volume or the proportion of $\mathrm{Ki}^{2} 7^{+}$cells in the U87MG tumor, MSCs are reported to facilitate tumor growth through their secretion of various anti-inflammatory cytokines and proangiogenic factors [41, 46-48]. Furthermore, MSCs can differentiate into cancer-associated fibroblasts (CAFs), which have been described in the stroma of carcinomas and are known to promote tumor growth [46]. In the GB peritumoral environment, we identified MSC-like cells that we named GB-associated stromal cells (GASCs) which have phenotypic and functional properties in common with MSCs and CAFs [51-53]. Like unprimed MSCs, their injection into intracranial U87MG tumors had no effect on tumor volume but promoted angiogenesis with an increase in the number of intratumoral small vessels [52]. Other studies isolated MSC-like cells from GB and these cells were shown to increase angiogenesis, and GB cell proliferation and invasion [54-58]. Consistent with these findings, it has been recently observed that the percentage of GB-associated MSC-like cells is inversely correlated with overall survival, indicating a role for these cells in promoting the aggressive behavior of GB $[59,60]$. All these data raise the question if MSCs are interesting candidates as cellular vehicles for the delivery of a therapeutic molecule in a GB context. Even if MSCs have the potential to deliver the therapeutic agent in the tumor, their pro-tumorigenic and pro-angiogenic properties may limit the effect of this agent. We need to find ways of guaranteeing the safety of this cellular vector for clinical use. One possibility would be to use a suicidal gene or a small molecule to induce senescence in the MSCs after drug delivery.

\section{Conclusion}

This study demonstrates the capacity of MSCs to carry SFN to GB after their intranasal administration and to decrease angiogenesis. Despite this encouraging result, the anti-angiogenic effect was not enough to affect tumor growth. The pro-tumorigenic and pro-angiogenic properties of MSCs may be responsible for the weakness of the therapeutic effect observed, and the SFN released may not be sufficient to counteract these MSC properties. These findings call into question the suitability of MSCs for use in the cell-based delivery of therapeutic agents for GB treatment.

\section{Abbreviations}

FISH: Fluorescence in situ hybridization; GB: Glioblastoma; HUVEC: Human umbilical vein endothelial cell; MRI: Magnetic resonance imaging

\section{Acknowledgements}

We thank "la coordination hospitalière des prélèvements d'organes et de tissus" (CHU, Angers, France). We are most grateful to the PRISM core facility and in particular to Dr. F Franconi (Rennes-Angers, France) for her technical 
support. We also thank P. Legras and J. Roux (Service commun d'animalerie Hospitalo-Universitaire, Angers, France), Prof. P. Schiller (University of MIAMI, School of Medicine, USA), Dr. L. Lemaire (INSERM U1066, Angers, France), L. Sindji (CRCINA, INSERM U1232, Angers, France), Chloé Appocher and Julie Renaud for providing facilities, and A. Edelman and Associates for correcting the manuscript.

\section{Funding}

This research was supported by grants from "Fondation de France", "Ligue contre le Cancer du Grand-Ouest, comité départemental du Maine-et-Loire", "Association en avant la vie" and the European Commission, Education, Audiovisual and Culture Executive Agency (EACEA), through the NanoFar Erasmus Mundus joint Doctoral program.

\section{Authors' contributions}

AC and PM developed the idea for the study. AC performed in vitro cell experiments and surgical procedures on small animals and wrote the manuscript. MPM, NL and ER performed HPLC and LC-MS/MS analyses. CMM provided human MSCs and contributed in the redaction of the manuscript. All authors read and approved the final manuscript.

\section{Ethics approval and consent to participate}

The procedure on animals was approved by the Committee on the Ethics of Animal Experiments of the "Pays de la Loire" (Permit no. 01785.01).

\section{Consent for publication}

Not applicable.

\section{Competing interests}

The authors declare that they have no competing interests.

\section{Publisher's Note}

Springer Nature remains neutral with regard to jurisdictional claims in published maps and institutional affiliations.

\section{Author details}

${ }^{1}$ Département de Neurochirurgie, CHU, Angers, France. ${ }^{2}$ CRCINA, INSERM, Université de Nantes, Université d'Angers, Angers, France. ${ }^{3}$ Division of Drug Delivery and Tissue Engineering, School of Pharmacy, University of Nottingham, Nottingham, UK. ${ }^{4}$ MINT, UNIV Angers, INSERM 1066, CNRS 6021, Université Bretagne Loire, Angers, France.

\section{Received: 20 June 2017 Accepted: 21 September 2017} Published online: 29 September 2017

\section{References}

1. Stupp R, Mason WP, van den Bent MJ, Weller M, Fisher B, Taphoorn MJB, et al. Radiotherapy plus concomitant and adjuvant temozolomide for glioblastoma. N Engl J Med. 2005;352:987-96.

2. Stupp R, Hegi ME, Mason WP, van den Bent MJ, Taphoorn MJB, Janzer RC, et al. Effects of radiotherapy with concomitant and adjuvant temozolomide versus radiotherapy alone on survival in glioblastoma in a randomised phase III study: 5-year analysis of the EORTC-NCIC trial. Lancet Oncol. 2009;10:459-66.

3. Polivka J, Polivka J, Holubec L, Kubikova T, Priban V, Hes O, et al. Advances in Experimental Targeted Therapy and Immunotherapy for Patients with Glioblastoma Multiforme. Anticancer Res. 2017;37:21-33.

4. Staedtke $V$, Bai R-Y, Laterra J. Investigational new drugs for brain cancer. Expert Opin Investig Drugs. 2016:25:937-56.

5. Kang JH, Adamson C. Novel chemotherapeutics and other therapies for treating high-grade glioma. Expert Opin Investig Drugs. 2015;24:1361-79.

6. Wilhelm S, Carter C, Lynch M, Lowinger T, Dumas J, Smith RA, et al. Discovery and development of sorafenib: a multikinase inhibitor for treating cancer. Nat Rev Drug Discov. 2006;5:835-44

7. Carra E, Barbieri F, Marubbi D, Pattarozzi A, Favoni RE, Florio T, et al. Sorafenib selectively depletes human glioblastoma tumor-initiating cells from primary cultures. Cell Cycle Georget Tex. 2013;12:491-500

8. Siegelin MD, Raskett CM, Gilbert CA, Ross AH, Altieri DC. Sorafenib exerts anti-glioma activity in vitro and in vivo. Neurosci Lett. 2010;478:165-70.

9. Yang F, Brown C, Buettner R, Hedvat M, Starr R, Scuto A, et al. Sorafenib induces growth arrest and apoptosis of human glioblastoma cells through the dephosphorylation of signal transducers and activators of transcription 3. Mol Cancer Ther. 2010;9:953-62.

10. Peereboom DM, Ahluwalia MS, Ye X, Supko JG, Hilderbrand SL, Phuphanich $S$, et al. NABTT 0502: a phase II and pharmacokinetic study of erlotinib and sorafenib for patients with progressive or recurrent glioblastoma multiforme. Neuro-Oncol. 2013;15:490-6.

11. Lee EQ, Kuhn J, Lamborn KR, Abrey L, DeAngelis LM, Lieberman F, et al. Phase I/II study of sorafenib in combination with temsirolimus for recurrent glioblastoma or gliosarcoma: North American Brain Tumor Consortium study 05-02. Neuro-Oncol. 2012;14:1511-8.

12. Hottinger AF, Aissa AB, Espeli V, Squiban D, Dunkel N, Vargas Ml, et al. Phase I study of sorafenib combined with radiation therapy and temozolomide as first-line treatment of high-grade glioma. Br J Cancer. 2014;110:2655-61.

13. Den RB, Kamrava M, Sheng Z, Werner-Wasik M, Dougherty E, Marinucchi M, et al. A phase I study of the combination of sorafenib with temozolomide and radiation therapy for the treatment of primary and recurrent highgrade gliomas. Int J Radiat Oncol Biol Phys. 2013;85:321-8.

14. Hassler MR, Ackerl M, Flechl B, Sax C, Wöhrer A, Widhalm G, et al. Sorafenib for patients with pretreated recurrent or progressive high-grade glioma: a retrospective, single-institution study. Anti-Cancer Drugs. 2014;25:723-8.

15. Zustovich F, Landi L, Lombardi G, Porta C, Galli L, Fontana A, et al. Sorafenib plus daily low-dose temozolomide for relapsed glioblastoma: a phase II study. Anticancer Res. 2013;33:3487-94

16. Reardon DA, Vredenburgh JJ, Desjardins A, Peters K, Gururangan S, Sampson $\mathrm{JH}$, et al. Effect of CYP3A-inducing anti-epileptics on sorafenib exposure: results of a phase II study of sorafenib plus daily temozolomide in adults with recurrent glioblastoma. J Neuro-Oncol. 2011;101:57-66.

17. Roger M, Clavreul A, Sindji L, Chassevent A, Schiller PC, Montero-Menei CN, et al. In vitro and in vivo interactions between glioma and marrow-isolated adult multilineage inducible (MIAMI) cells. Brain Res. 2012;1473:193-203.

18. Mangraviti A, Tzeng SY, Gullotti D, Kozielski KL, Kim JE, Seng M, et al. Nonvirally engineered human adipose mesenchymal stem cells produce BMP4, target brain tumors, and extend survival. Biomaterials. 2016;100:53-66.

19. Balyasnikova IV, Prasol MS, Ferguson SD, Han Y, Ahmed AU, Gutova M, et al. Intranasal delivery of mesenchymal stem cells significantly extends survival of irradiated mice with experimental brain tumors. Mol Ther. J. Am. Soc Gene Ther. 2014;22:140-8.

20. Pacioni S, D'Alessandris QG, Giannetti S, Morgante L, Coccè V, Bonomi A, et al. Human mesenchymal stromal cells inhibit tumor growth in orthotopic glioblastoma xenografts. Stem Cell Res Ther. 2017;8:53.

21. Menon LG, Pratt J, Yang HW, Black PM, Sorensen GA, Carroll RS. Imaging of human mesenchymal stromal cells: homing to human brain tumors. J NeuroOncol. 2012;107:257-67.

22. Binello E, Germano IM. Stem cells as therapeutic vehicles for the treatment of high-grade gliomas. Neuro-Oncol. 2012;14:256-65.

23. Roger M, Clavreul A, Venier-Julienne M-C, Passirani C, Montero-Menei C, Menei $P$. The potential of combinations of drug-loaded nanoparticle systems and adult stem cells for glioma therapy. Biomaterials. 2011;32:2106-16.

24. Bexell D, Svensson A, Bengzon J. Stem cell-based therapy for malignant glioma. Cancer Treat Rev. 2013;39:358-65.

25. Aleynik A, Gernavage KM, Mourad YS, Sherman LS, Liu K, Gubenko YA, et al. Stem cell delivery of therapies for brain disorders. Clin Transl Med. 2014;3:24.

26. Bhere D, Shah K. Stem Cell-Based Therapies for Cancer. Adv Cancer Res. 2015;127:159-89.

27. Namba H, Kawaji H, Yamasaki T. Use of genetically engineered stem cells for glioma therapy. Oncol Lett. 2016;11:9-15.

28. Zhang X-B, Beard BC, Trobridge GD, Wood BL, Sale GE, Sud R, et al. High incidence of leukemia in large animals after stem cell gene therapy with a HOXB4-expressing retroviral vector. J Clin Invest. 2008;118:1502-10.

29. Roger M, Clavreul A, Huynh NT, Passirani C, Schiller P, Vessières A, et al. Ferrociphenol lipid nanocapsule delivery by mesenchymal stromal cells in brain tumor therapy. Int J Pharm. 2012:423:63-8.

30. Li L, Guan Y, Liu H, Hao N, Liu T, Meng X, et al. Silica nanorattle-doxorubicinanchored mesenchymal stem cells for tumor-tropic therapy. ACS Nano. 2011;5:7462-70.

31. Clavreul A, Montagu A, Lainé A-L, Tétaud C, Lautram N, Franconi F, et al. Targeting and treatment of glioblastomas with human mesenchymal stem cells carrying ferrociphenol lipid nanocapsules. Int J Nanomedicine. 2015;10:1259-71.

32. Pacioni S, D'Alessandris QG, Giannetti S, Morgante L, De Pascalis I, Coccè V, et al. Mesenchymal stromal cells loaded with paclitaxel induce cytotoxic damage in glioblastoma brain xenografts. Stem Cell Res Ther. 2015;6:194. 
33. Zhang X, Yao S, Liu C, Jiang Y. Tumor tropic delivery of doxorubicinpolymer conjugates using mesenchymal stem cells for glioma therapy. Biomaterials. 2015;39:269-81.

34. Pessina A, Bonomi A, Coccè V, Invernici G, Navone $S$, Cavicchini $L$, et al. Mesenchymal stromal cells primed with paclitaxel provide a new approach for cancer therapy. PLoS One. 2011;6:e28321.

35. Fischer UM, Harting MT, Jimenez F, Monzon-Posadas WO, Xue H, Savitz SI, et al. Pulmonary passage is a major obstacle for intravenous stem cell delivery: the pulmonary first-pass effect. Stem Cells Dev. 2009;18:683-92.

36. Ramot Y, Steiner M, Morad V, Leibovitch S, Amouyal N, Cesta MF, et al. Pulmonary thrombosis in the mouse following intravenous administration of quantum dot-labeled mesenchymal cells. Nanotoxicology. 2010;4:98-105.

37. Danielyan L, Schäfer R, von Ameln-Mayerhofer A, Buadze M, Geisler J, Klopfer T, et al. Intranasal delivery of cells to the brain. Eur J Cell Biol. 2009;88:315-24

38. Danielyan L, Beer-Hammer S, Stolzing A, Schäfer R, Siegel G, Fabian C, et al. Intranasal delivery of bone marrow-derived mesenchymal stem cells, macrophages, and microglia to the brain in mouse models of Alzheimer's and Parkinson's disease. Cell Transplant. 2014;23(Suppl 1):S123-39.

39. van Velthoven CTJ, Kavelaars A, van Bel F, Heijnen CJ. Nasal administration of stem cells: a promising novel route to treat neonatal ischemic brain damage. Pediatr Res. 2010;68:419-22.

40. D'Ippolito G, Diabira S, Howard GA, Menei P, Roos BA, Schiller PC. Marrowisolated adult multilineage inducible (MIAMI) cells, a unique population of postnatal young and old human cells with extensive expansion and differentiation potential. J Cell Sci. 2004;117:2971-81.

41. Sherman LS, Shaker M, Mariotti V, Rameshwar P. Mesenchymal stromal/stem cells in drug therapy: New perspective. Cytotherapy. 2017;19:19-27.

42. Pascucci L, Coccè V, Bonomi A, Ami D, Ceccarelli $P$, Ciusani E, et al. Paclitaxel is incorporated by mesenchymal stromal cells and released in exosomes that inhibit in vitro tumor growth: a new approach for drug delivery. J Control Release. 2014;192:262-70.

43. Del Fattore A, Luciano R, Saracino R, Battafarano G, Rizzo C, Pascucci L, et al. Differential effects of extracellular vesicles secreted by mesenchymal stem cells from different sources on glioblastoma cells. Expert Opin Biol Ther. 2015;15:495-504.

44. Reitz M, Demestre M, Sedlacik J, Meissner H, Fiehler J, Kim SU, et al. Intranasal delivery of neural stem/progenitor cells: a noninvasive passage to target intracerebral glioma. Stem Cells Transl Med. 2012;1:866-73.

45. Lemée J-M, Clavreul A, Menei P. Intratumoral heterogeneity in glioblastoma: don't forget the peritumoral brain zone. Neuro-Oncol. 2015;17:1322-32.

46. Ridge SM, Sullivan FJ, Glynn SA. Mesenchymal stem cells: key players in cancer progression. Mol Cancer. 2017;16:31.

47. Zhang C, Yang S-J, Wen Q, Zhong JF, Chen X-L, Stucky A, et al. Human-derived normal mesenchymal stem/stromal cells in anticancer therapies. J Cancer. 2017:8:85-96.

48. Shi Y, Du L, Lin L, Wang Y. Tumour-associated mesenchymal stem/stromal cells: emerging therapeutic targets. Nat Rev Drug Discov. 2017;16:35-52.

49. Bronckaers A, Hilkens P, Martens W, Gervois P, Ratajczak J, Struys T, et al. Mesenchymal stem/stromal cells as a pharmacological and therapeutic approach to accelerate angiogenesis. Pharmacol Ther. 2014;143:181-96.

50. Merino-González C, Zuñiga FA, Escudero C, Ormazabal V, Reyes C, NovaLamperti E, et al. Mesenchymal Stem Cell-Derived Extracellular Vesicles Promote Angiogenesis: Potencial Clinical Application. Front Physiol. 2016;7:24.

51. Clavreul A, Etcheverry A, Chassevent A, Quillien V, Avril T, Jourdan M-L, et al. Isolation of a new cell population in the glioblastoma microenvironment. J Neuro-Oncol. 2012;106:493-504.

52. Clavreul A, Guette C, Faguer R, Tétaud C, Boissard A, Lemaire L, et al. Glioblastomaassociated stromal cells (GASCs) from histologically normal surgical margins have a myofibroblast phenotype and angiogenic properties. J Pathol. 2014;233:74-88.

53. Clavreul A, Etcheverry A, Tétaud C, Rousseau A, Avril T, Henry C, et al. Identification of two glioblastoma-associated stromal cell subtypes with different carcinogenic properties in histologically normal surgical margins. J Neuro-Oncol. 2015;122:1-10.

54. Appaix F, Nissou M-F, van der Sanden B, Dreyfus M, Berger F, Issartel J-P, et al. Brain mesenchymal stem cells: The other stem cells of the brain? World J Stem Cells. 2014;6:134-43.

55. Kong BH, Shin H-D, Kim S-H, Mok H-S, Shim J-K, Lee J-H, et al. Increased in vivo angiogenic effect of glioma stromal mesenchymal stem-like cells on glioma cancer stem cells from patients with glioblastoma. Int J Oncol. 2013;42:1754-62.
56. Lim E-J, Suh Y, Yoo K-C, Lee J-H, Kim I-G, Kim M-J, et al. Tumor-associated mesenchymal stem-like cells provide extracellular signaling cue for invasiveness of glioblastoma cells. Oncotarget. 2017;8:1438-48.

57. Hossain A, Gumin J, Gao F, Figueroa J, Shinojima N, Takezaki T, et al. Mesenchymal Stem Cells Isolated From Human Gliomas Increase Proliferation and Maintain Stemness of Glioma Stem Cells Through the IL-6/gp130/STAT3 Pathway. Stem Cells Dayt Ohio. 2015;33:2400-15.

58. Svensson A, Ramos-Moreno T, Eberstål S, Scheding S, Bengzon J. Identification of two distinct mesenchymal stromal cell populations in human malignant glioma. J Neuro-Oncol. 2017;131:245-54.

59. Shahar T, Rozovski U, Hess KR, Hossain A, Gumin J, Gao F, et al. Percentage of mesenchymal stem cells in high-grade glioma tumor samples correlates with patient survival. Neuro-Oncol. 2017;19:660-68.

60. Yoon S-J, Shim J-K, Chang JH, Moon JH, Roh T-H, Sung KS, et al. Tumor Mesenchymal Stem-Like Cell as a Prognostic Marker in Primary Glioblastoma. Stem Cells Int. 2016;2016:6756983.

\section{Submit your next manuscript to BioMed Central and we will help you at every step:}

- We accept pre-submission inquiries

- Our selector tool helps you to find the most relevant journal

- We provide round the clock customer support

- Convenient online submission

- Thorough peer review

- Inclusion in PubMed and all major indexing services

- Maximum visibility for your research

Submit your manuscript at www.biomedcentral.com/submit
Biomed Central 